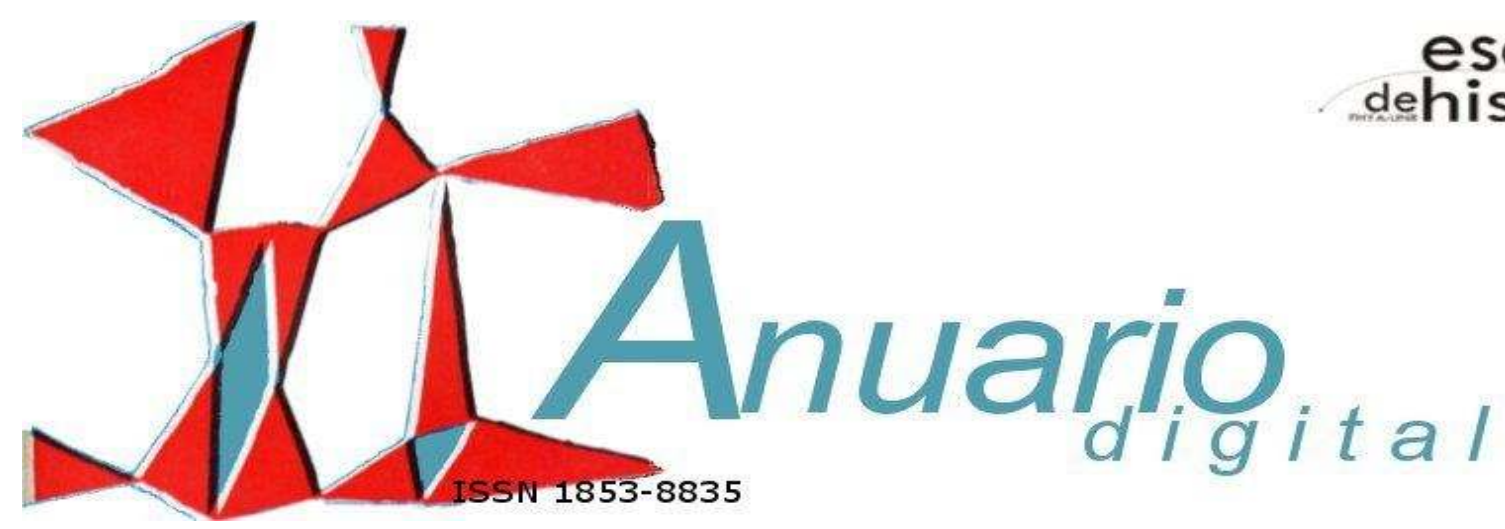

\title{
MÁS ALLÁ DEL ESPACIO: POR UNA HISTORIA CULTURAL DE LO URBANO*
}

Desde fin del siglo XX, la ampliamente discutida crisis de los paradigmas explicativos de la "realidad" puso a prueba a la llamada "nueva historia cultural", que tiene un amplio campo de aplicación en los estudios relacionados con las representaciones sociales de la ciudad. Al comprender el fenómeno urbano como una acumulación de bienes culturales, el artículo busca desplegar estrategias metodológicas y teóricas que nos permitan una lectura de la ciudad. A través del sistema históricamente construido de ideas e imágenes de la representación colectiva que llamamos imaginario, se propone alcanzar lo "real".

Palabras clave: Ciudad - imaginación - narración - representaciones - cultura

\footnotetext{
* Este trabajo fue publicado por primera vez en portugués bajo este título "Moito além do espaço: por uma história cultural do urbano"; en la revista Estudios Históricos (v. 8, № 16;1995; pp. 279-290). Agradecemos a los editores por permitirnos efectuar esta republicación en español. Traducción Diego P. Roldán.
} 
Since the late twentieth century, the widely discussed crisis of scientific paradigms and the concept of "reality" tested the "new cultural history" history", which has a wide application in the studies related to social representation of the city. Understanding the urban phenomenon as an accumulation of cultural meanings, the article seeks to development methodological and theoretical strategies for reading the cultural forms of the city. The imagination is the system historically constructed by ideas and images of collective representation; through the imagination we aim to achieve the "real".

Key words: City - imagination - narration - representations - culture

"En Le temps retrouvé, última parte de À la recherche du temps perdu, Marcel Proust es invitado una mañana a la casa de la princesa de Guermantes, Esperando en el salón-biblioteca, él reencuentra el sabor de madeleine, y luego invoca la realidad del tiempo pasado como una cierta relación entre sensaciones y recuerdos"

Le Nouvelle Observateur; marzo 1995; p. 5

Este resurgimiento del pasado se genera por la combinación de una experiencia, o por la renovación de la sensación de lo vivido -el acto de comer la madeleine-, como la evocación que inaugura una nueva temporalidad a través de un pasado que se hace presente. De esta forma la combinación memoria/recuerdo como la sensación/vivencia (re)presenta algo distante en el tiempo y en el espacio y que se coloca en lugar de lo ocurrido. Estaríamos delante de una de las corrientes centrales del nuevo paradigma que se propone sustituir a la destrucción del conjunto de ideas y certezas heredadas del siglo XIX que se encuentra en la difundida crisis de nuestros tiempos actuales.

En términos teóricos-metodológicos, juzgamos que los estudios de historia cultural están a la orden del día en la historiografía mundial, pudiendo incluso decirse que constituyen la "punta fina" de este final de

40

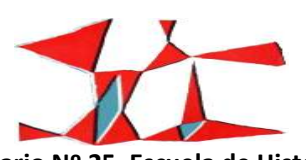

Anuario № 25, Escuela de Historia

Revista Digital № 4, Facultad de Humanidades y Artes, Universidad Nacional de Rosario, 2013

ISSN 1853-8835 
siglo. Entendida como el desbordamiento de la historia social ${ }^{1}$ que, a su vez, se presentaba como la vertiente resultante de la confluencia de las historiografías inglesa ${ }^{2}$ y francesa ${ }^{3}$, la llamada nueva historia cultural se encuentra difundida por Alemania, ${ }^{4}$ Estados Unidos, ${ }^{5}$ sin mencionar tradiciones más antiguas, como la italiana. ${ }^{6}$ Se puede incluso afirmar que los debates en torno a la historia cultural y del sistema de ideas-imágenes que le da soporte -el imaginario social ${ }^{7}$ - son elementos catalizadores del pensamiento académico contemporáneo. Entendemos a la historia cultural no como un giro retórico con relación a los presupuestos teórico-metodológicos, sino como un nuevo abordaje, una nueva mirada que se apoya sobre los análisis ya realizados, y, a su vez, avanza dentro de un determinado enfoque. En este sentido, la historia cultural realmente viene a sumarse al conocimiento acumulado, sin dar la espalda a una matriz teórica, fruto de una reflexión acumulativa.

Pensar lo social a través de sus representaciones es, a nuestro modo de ver, una preocupación contemporánea al fin del siglo XX, señalada por la crisis de los paradigmas explicativos de la realidad que pone en jaque la objetividad y la racionalidad de las leyes científicas en el dominio de las ciencias humanas. Asumir esta postura metodológica implica alcanzar lo "real "a través de sus representaciones y comporta partir de determinado "corpus teórico".

El primer campo a ser definido sería el de la representación. La utilización de este concepto, que implica el retorno a Durkheim y a Mauss ${ }^{8}$ se convirtió en una categoría central para los análisis de la nueva historia cultural. El concepto, en sí, envuelve una serie de consideraciones, comenzando por el presupuesto de que la representación implica una relación ambigua entre ausencia y presencia. En todo caso, la representación es la presentación de un ausente, que es presentado a través de una imagen, mental o material, que se distancia del mimetismo puro y simple y trabaja con una atribución de sentido.

\footnotetext{
${ }^{1}$ Hunt, Lynn; The new cultural history; University of California Press; California; 1989.

${ }^{2}$ Principalmente los nuevos marxistas ingleses E. P. Thompson, Christopher Hill y Raymond Willams.

${ }^{3}$ En especial el grupo Nueva Historia: Roger Chartier, Jacques Le Goff, Jacques Ranciere, Jacques Revel y Alain Brouguière.

${ }^{4}$ Carl Schorseke y Hans Medick.

${ }^{5}$ Lynn Hunt, Natalie Zemon Davis y Robert Darnton, sólo para citar a los más conocidos para el público brasileño.

${ }^{6}$ Es el caso específico del muy celebrado Ginzburg, Carlo; O queijo e os vermes; Companhia das Letras; São Paulo; 1987.

${ }^{7}$ Baczko, Bronislaw; Les imaginaires sociaux; Payot; París; 1984.

${ }^{8}$ Mauss, Marcel; Represéntations collectives et diversité des civilizations; Ed. Minuit; París; (Oeuvres, 3); 1969.
}

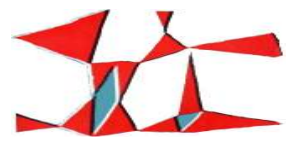

Anuario № 25, Escuela de Historia 
Para Chartier ${ }^{9}$ la noción de representación es central en su concepción de la historia cultural, que esencialmente se despliega en la relación entre prácticas sociales y representaciones. La representación deja ver una ausencia, estableciéndose la diferencia entre aquello que representa (el representante) y lo que es representado. Pero, al mismo tiempo, la representación afirma una presencia de aquello que se expone en el lugar de lo otro. Entre una y otra función, se produce la construcción de un sentido, siendo la tarea del historiador alcanzar esta inteligibilidad, ${ }^{10}$ usando el concepto como instrumento para interrogar al mundo, garantizando su inserción como categoría central de una nueva episteme para la historia.

Observar la realidad bajo este prisma implica colocarse en el núcleo de la redefinición paradigmática de la historia. Nos parece particularmente interesante la discusión abierta por Jean Boutier y Dominique Julia $^{11}$, y que se sitúa frente a la necesidad de establecer nuevos paradigmas para el conocimiento teórico.

La alternativa propuesta se encamina en el sentido tanto de reconstruir una nueva totalidad cuanto de encontrar nuevas vías teórico-metodológicas para realizar el análisis histórico. Un primer paso sería la comprensión de que la cultura podría ocupar el lugar de una instancia más central y globalizadora que reorientase la mirada sobre lo real. Tal postura, desde nuestro punto de vista, inquietante, confluye con una moderna tendencia de análisis en la historiografía, que aborda los sistemas simbólicos de ideas e imágenes de representación colectiva a la que se da el nombre de imaginario social.

Según esta tendencia la tarea del historiador sería captar la pluralidad de los sentidos y rescatar la construcción de significados que preside a lo que llamaría la "representación del mundo". Pero hay más, tomamos como presupuesto que la historia es, ella misma, representación de algo que habría ocurrido un día. Distinguiríamos, por tanto, lo que llamaría “Pasado"12 (el real acontecido) de la "Historia", entendida como narrativa que representa a través del texto y la imagen. Asumir esta postura -según Rüssen

\footnotetext{
${ }^{9}$ Chartier, Roger; "Le monde comme répresentation"; en Annales; V.6; nov.-dez 1989; pp. 1513-5. A história cultural: entre práticas e representações; Difel; Lisboa; 1990. "A história hoje: dúvidas, desafios, propostas”; en Estudos Históricos; № 13; jan.-jun 1994. "L'histoire culturelle aujourd'hui"; en Genèses; № 15; 1994.

${ }^{10}$ Para la categoría de representación, consultar, además de las obras de Chartier: Berían, Josetxo; Representaciones colectivas y proyecto de modernidad; Antropos; Barcelona; 1990. Bourdieu, Pierre; O poder simbólico; Difel; Lisboa; 1989 y Ce que parler veut dire; Fayard; París; 1992. Ginzburg, Carlo; "Représentation: le mot, l'idée, la chose"; Annales; V. 6; nov-dez 1996. Marin, Luis; Des pourvoirs de l' image; Seuil; París; 1993 y De la représentation; Gallimard; Seuil; París; 1994. Ricoeur, Paul; De texte a l' action; Espirit/Seuil; París; 1986.

${ }^{11}$ Boutier, Jean y Julia, Dominique; “Ouverture: à quoi pensent les historiens?”; en Passés recomposés. Champs et chantiers de l'histoire; Autrement; París; 1995.

12 "Passeidade" en el original. N. T.
}

42

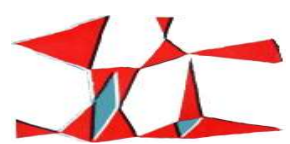

Anuario № 25, Escuela de Historia

Revista Digital № 4, Facultad de Humanidades y Artes, Universidad Nacional de Rosario, 2013 ISSN 1853-8835 
posmoderna ${ }^{13}$ - implica admitir que no hay un único proceso comprensivo para la historia, más allá de admitir criterios como el de ficción o el de relativismo para la recuperación del pasado. Si el "Pasado" es algo que ocurre por fuera de la experiencia de lo vivido y si los registros de su acaecimiento ya nos llegan como representaciones de algo que irremisiblemente dejó de ser, la historia al ser construida se representa como una posibilidad entre otras de captar el pasado. No es nuestra intención retomar todas las facetas que este abordaje implica o todos los problemas que enfrenta, aunque sí enfocar una de sus vertientes de investigación, que toma a la ciudad como objeto de reflexión.

En este contexto, con este trabajo pretendemos rescatar a la ciudad a través de las representaciones, entendiendo el fenómeno urbano como una acumulación de bienes culturales. ${ }^{14}$ Entonces, considerando a la cultura como una red de significados socialmente establecidos ${ }^{15}$, la ciudad es el espacio por excelencia para la construcción de estos significados, expresados bajo la forma de bienes culturales. Nuestro intento es, pues, rescatar a la ciudad "real" a través de la "lectura de las ciudades", o de sus representaciones. Entender la cuestión de este modo no es someterla a un simple juego de palabras, especialmente si partimos del presupuesto de que las representaciones son parte integrante de aquellos que llamamos realidad. Esta especie de simbiosis entre lo representado y lo real se genera no sólo porque los esquemas culturales son matrices generadoras de prácticas sociales, sino también porque demuestran un esfuerzo de revelación/ocultamiento dado tanto respecto a las imágenes reales (escenarios, paisajes de la calle, arquitectura) como a las imágenes metafóricas (de la literatura, pintura, poesía, discurso técnico e higienista, etc.). ${ }^{16}$

Entendemos pues que la ciudad posibilita una "iluminación", expresión tomada en el sentido benjaminiano del término ${ }^{17}$ de revelación, inteligibilidad, cruzamiento del dato objetivo (la obra, el trazo, la señal) con el subjetivo (la lectura de la representación).

\footnotetext{
${ }^{13}$ Rüssen, John; “La história, entre modernidad y post-modernidad”; en Gallego, José Andrés (org); New History, Nouvelle Histoire; hacia una nueva história; Actas; Madrid; 1992.

${ }^{14}$ Argan, Giulio Carlo; História da arte como história da cidade; São Paulo; Martins Fontes; 1992.

${ }^{15}$ Geertz, Clifford; A interpretação das culturas; Guanabara; Rio de Janeiro; 1981.

${ }^{16}$ Pechman, Robert Moses; "Um olhar sobre a cidade: estudo de imagem e do imaginário do Rio na formação da modernidade"; en Fernandez, Ana e Gomes, Marco Aurélio; Cidade e história; UFBA/ ANPUB; Salvador; 1992.

${ }^{17}$ Petitdemange, Guy; “Avant le monumental, les passages: Walter Benjamin”; en Baudrillard, Jean et al. Citoyennité et urbanite; Esprit; París; 1991.
}

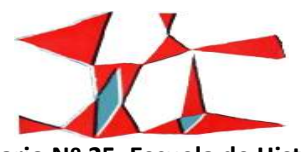

Anuario № 25, Escuela de Historia 
La ciudad es como se sabe una relación muy antigua. De la Ur de los Zigurats a la Tebas de las Siete Puertas, de la Roma de los Césares, a la Avignon de los Papas ella marca su presencia en la historia, a través de los elementos que señalan el advenimiento de lo que se considera civilización. Pero es sobre todo con el advenimiento del capitalismo que se impone la "cuestión urbana" colocando delante del Estado la exigencia de un modus vivendi normalizador del "vivir en ciudades". Procesos económicos y sociales muy claros se delinean, transformando las condiciones de existencia: concentraciones de población, migraciones rurales, superpoblamiento y mutaciones del espacio, señalan el crecimiento y la configuración de las ciudades.

En rigor, ya existe un significativo conocimiento acumulado en términos de estudios urbanos, que nos fue legado por una historia económico-social concentrada sobre los orígenes y el desarrollo del capitalismo y de la sociedad burguesa y que tuvo en la ciudad su espacio privilegiado de análisis. Como refiere Pinol $^{18}$, la historia urbana no tuvo la misma importancia y/o dimensión en todos los países del mundo occidental, siendo Inglaterra y los Estados Unidos pioneros en esta área. ${ }^{19}$ En Francia, la línea histórico-social de las ciudades encontraría su gran expresión en la voluminosa colección dirigida por Georges Duby ${ }^{20}$, complementada por los trabajos de Murard y Zylberman ${ }^{21}$, Yves Lequin ${ }^{22}$, Bernard Lepetit $^{23}$, Jean Luc Pinol ${ }^{24}$, Bourillon, ${ }^{25}$ Michelle Perrot $^{26}$, Louis Chevallier ${ }^{27}$ y Christian Topalov ${ }^{28}$. En el caso

\footnotetext{
${ }^{18}$ Pinol, Jean Luc; Le monde des villes au XIXe siècle; Hachette; París; 1991.

${ }^{19}$ A partir de la obra clásica de Dyos, H. J.; Victorian suburbs: a study of the growth of Camberwell; Leicester University Press; London; 1961 se destacan algunas de las obras que darían inicio a la New Urban History, como la de Thernstorn, Stephan y Sennett, Richard; Nineteenth century cities Essays in New York history; Yale University Press; New Haven; 1969; lo mismo que la muy conocida obra de Thompson, E. P.; The making of the English working class; Pantheon Books; London; 1963. En los Estados Unidos se puede mencionar el ya clásico libro de Ternstorn, Stephan; Poverty and progress, social mobility in a nineteenth century city; Harvard University Press; Massachusets; 1964.

${ }^{20}$ Duby, Georges (org.); Histoire de la France urbaine; 4. Vols; Le Seuil; París; 1983.

${ }^{21}$ Murard, Léon y Zylberman, Patrick; “Le petit travailleur infatigable: villes, usines, habitats et intimités au XIXe siècle”; en Recherches; № 25; 1976. Murard, Léon; "L'haleine des faubourgs: ville, habitat et santé au XIXe siècle"; en Recherches; № 29; 1978.

${ }^{22}$ Lequin, Yves; "Les débats et les tensions de la societé industrielle"; en Léon, Pierre (ed.); Histoire économique et sociale du monde, 1840-1914; t. 4; Armand Colin; París; 1978.

${ }^{23}$ Lepetit, Bernard; Les villes dans la France moderne (1740-1840); Albin Michel; París; 1988. Lepetit, Bernard y Pumain, Denise; Temporalités urbaines; Anthropos; París; 1993.

${ }^{24}$ Pinol, Jean Luc; Le monde des villes au XIXe siècle; Ob. Cit.

${ }^{25}$ Bourillon, F.; Les villes en France au XIXe siècle; Ophrys; París; 1992.

${ }^{26}$ Perrot, Michelle; "Les ouvriers, I'habitat et la ville au XIXe siècle”; en La question du logement et le mouvement ouvrier français; Éd. de la Villete; París; 1981.

${ }^{27}$ Chevallier, Louis; Classes laborieuses et classes dangereuses à París pendant la première moitié du XIXe siècle; Pluriel; París; 1978.

${ }^{28}$ Topalov, Christian; Le logement en France; histoire d'une marchandise imposible; Presses de la Fondation Nationale des Sciences Politiques; París; 1987. Topalov, Christian; “De la 'cuestión social' a los 'problemas urbanos'; los reformadores y la población de las metrópolis a principios del siglo XX"; Revista Internacional de Ciencias Sociales; Unesco; set. 1990.
}

44

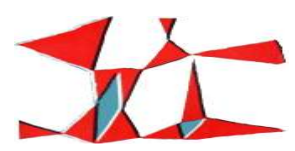

Anuario № 25, Escuela de Historia

Revista Digital № 4, Facultad de Humanidades y Artes, Universidad Nacional de Rosario, 2013 ISSN 1853-8835 
brasileño hay que citar a la persistente regionalización de los estudios que va desde análisis más amplios y profundos, resultantes de tesis, a artículos, ensayos u obras de divulgación. ${ }^{29}$

Pero, como ya fue anunciado, nos interesa la profundización en una historia cultural de lo urbano, donde se crucen los datos objetivos -obras, trazos, señales o "fragmentos" del pasado que nos llegan, bajo la forma de imágenes o discursos, con las posibilidades de lectura que la ciudad ofrece-.

Emprender ese camino presupone pensar más allá del espacio, apuntando al camino de las representaciones simbólicas de la urbe, que pueden corresponder o no a la realidad sensible, sin que por eso pierdan su forma imaginaria. Como se sabe, la idea o concepción de una ciudad para que sea una metrópolis debe estar bien asociada a datos concretos y evidentes, tales como patrón de edificación, número de población, sistema de servicios urbanos implementados, red viaria, infraestructura de ocio y comercial, etc. Metrópolis fueron París y Londres, así como Nueva York, San Pablo y también Río de Janeiro. O sea, estos centros urbanos comportan la materialización, en el tiempo y el espacio, de un fenómeno social que dio margen al concepto de metrópolis. ¿Pero qué pensar de la Porto Alegre de los años 1930s., matrizada según los patrones urbanos vigentes, y que es narrada por sus contemporáneos como metrópolis evidenciando el "ritmo alucinante" de "progreso" y desarrollo, tal como dicen los periódicos de la época?

Debemos entender que el espacio construido, ordenado y transformado -por la destrucción de los callejones, la abertura de la avenida Borges de Medeiros, la construcción del viaducto- suscitó sensaciones, percepciones y la elaboración de representaciones para aquellos que experimentaron el proceso de transformación en la ciudad. Sin duda, estas experiencias eran elaboradas y comparadas a partir del consumo de patrones de referencia ya establecidos: largas avenidas o viaductos o el saneamiento urbano, como la "Barriada de los pobres" del centro de la ciudad, eran prácticas ligadas al concepto de ciudad

\footnotetext{
${ }^{29}$ Atendiendo a esta regionalización de las perspectivas, conviene citar en el caso bahiano, las obras de Queiroz Mattoso, Katia; $A$ cidade de Salvador e seu mercado no século XX; Hucitec; São Paulo; 1978 y Bahia, século XIX uma província no Império; Nova Fronteira; Rio de Janeiro; 1992. Las compilaciones organizadas por Fernandes, Ana y Gomes, Marco Aurélio; Cidade e história. Modernização das cidades brasileiras nos séculos XIX e XX; UFBA; Salvador; 1992 da cuenta de una región de Brasil como una totalidad, también la revista Espacio a Debate. En el caso de San Pablo hay que destacar las tesis defendidas en el programa de Posgrado de UNICAMP, así como la tesis de agregación de Glezer, Raquel, Chão de terra: um estudo sobre São Paulo colonial, defendida en la USP en 1992. En el caso de Río Grande do Sul, se registra la colección organizada por Panizzi, Wrana y Rovatti, João; Estudos urbanos: Porto Alegre e seu planejamento; Ed. da Universidade; Porto Alegre; 1993 y los libros de Pesavento, Sandra Jatahy; Memória Porto Alegre: espaços e vivências; Ed. da Universidade; Porto Alegre; 1991 e Os pobres da cidad; Ed. da Universidade; Porto Alegre; 1994. Para Río de Janeiro cabe recordar los avances realizados por el grupo que publicaba en la revista Río de Janeiro, los textos presentados en el seminario Río Republicano, de la Fundación Casa de Rui Barbosa (octubre de 1994) que centralizaron su enfoque en la ciudad de Río.
}

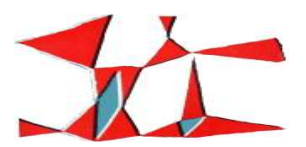

Anuario № 25, Escuela de Historia Revista Digital № 4, Facultad de Humanidades y Artes, Universidad Nacional de Rosario, 2013 ISSN 1853-8835 
moderna y de civilización. Exigencias morales, higiénicas y estéticas imperiosas se imponían delante de la necesidad de "ser" y "parecer" moderno.

Aunque el proceso de renovación urbana no se aproximase, en términos de escala, al de las metrópolis reales que soportaban el concepto, la población afectada por las demoliciones experimentaba la situación como una prueba necesaria para el acceso a la modernidad. En suma, los portoalegrenses sentían su ciudad como metrópolis y la representaban como tal en las crónicas de los diarios, poesías, imágenes y discursos variados.

Estaríamos delante de un imaginario social sobre la ciudad metrópolis que, sin correspondencia efectiva con el real concreto, tenía una existencia claramente delimitada para los patrones de referencia conceptual vigentes en el mundo capitalista. Podríamos tal vez decir que Porto Alegre se sentía metrópolis sin serlo realmente, pero esta sensibilidad hacía que la representación imaginaria ganase fuerza de realidad. En cierta forma, esta idea es esbozada por Marshall Berman ${ }^{30}$ en su celebrada obra, cuando dice que, para determinadas regiones -como la Rusia Zarista-, la modernidad aparece como algo distante, de la que se oye hablar, de lo que se tiene cierto conocimiento, que se desea experimentar, y que se mezcla, en ocasiones, en un único elemento, convertido en emblema de la modernidad. En este sentido, la avenida Borges de Medeiros de Porto Alegre y la Nevski Prospekt de San Petesburgo cumplirían el mismo papel de representación simbólica de la modernidad deseada.

De la misma forma, las representaciones construidas sobre lo urbano pueden, también, comprender o no los códigos iniciales y las intenciones de sus artífices ${ }^{31}$. Por ejemplo las construcciones y espacios de poder público pueden obedecer a una intencionalidad en cuanto proyecto y concepción, distante de las referencias simbólicas que su uso y consumo elaboran. O sea, en cuanto presentadores de propuestas para la ciudad, los urbanistas y arquitectos atribuyen una función, que podría distanciarse en mucho de las construcciones simbólicas hechas por aquellos usuarios de aquel espacio transformado.

\footnotetext{
${ }^{30}$ Berman, Marshall; Tudo que é sólido desmancha no ar; a aventura da modernidade; Companhia das Letras; São Paulo; 1986.

${ }^{31}$ Montlibert, Christian; de L'impossible autonomie de l'architecte; Presses Universitaires de Strasbourg; Strasbourg; 1995.
}

46

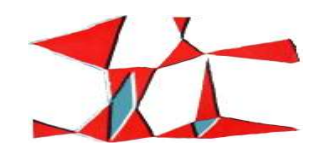

Anuario № 25, Escuela de Historia

Revista Digital № 4, Facultad de Humanidades y Artes, Universidad Nacional de Rosario, 2013 ISSN 1853-8835 
Hay que establecer la distinción trazada por Marcel Roncayolo ${ }^{32}$ entre productores y consumidores del espacio. Partiendo de la ciudad como representación o conjunto de representaciones, Roncayolo identifica que hay un sistema de ideas, más o menos coherente, que "hacen la ciudad", la proyectan, discuten y ejecutan. Los portadores de tales ideas serían identificados en el interior de las clases dominantes o de las élites dirigentes, destacándose especialmente los que llamaría "profesionales de la ciudad": arquitectos, urbanistas, ingenieros, médicos higienistas y los demás técnico-burócratas encargados de implementar los equipamientos necesarios para la intervención urbana. La denominación de Roncayolo tiene una datación precisa: el siglo XIX, cuando emerge la gran ciudad que impone a los gobiernos la necesidad de intervenir en el espacio, ordenando la vida y regulando la sociedad. La "cuestión urbana" aparece, entonces, como un problema candente, derivado de las transformaciones socioeconómicas de la época y que tiene en la ciudad su locus privilegiado de realización. ${ }^{33}$ Sin duda estos "productores del espacio" conciben una manera de construir y/o transformar la ciudad, a través de prácticas definidas, pero también construyen una manera de pensarla, viviéndola o la soñándola. Existe la proyección de una "ciudad que se quiere", imaginada y deseada, sobre la ciudad que se tiene un plan que puede verse realizado o no. Lo que importa rescatar, desde el punto de vista de la historia cultural urbana, es que la "ciudad del deseo", realizado o no, existió como elaboración simbólica en la concepción de quien la proyectó y la quiso concretar.

Pero Roncayolo no se restringe sólo a los portadores de tales ideas y ejecutores de tales prácticas sociales de intervención urbana y se pregunta por las representaciones de la ciudad que provienen de los consumidores del espacio o habitantes de la ciudad. En lo tocante a estos "espectadores de la urbe" hay que distinguir entre lo que podría llamarse "ciudadano común" o "gente sin importancia", que constituye la masa de la población citadina, y los que podrían ser denominados los "lectores especiales de la ciudad", representados por los fotógrafos, poetas, novelistas, cronistas y pintores de la ciudad. Naturalmente hay una variación de sensibilidad y de educación de la mirada entre los dos tipos de consumidores de la urbe.

\footnotetext{
${ }^{32}$ Roncayolo, Marcel; La ville et ses territoires; Gallimard; París; 1990.

${ }^{33}$ En cuanto al surgimiento de la "cuestión urbana", consultar Topalov, Christian; "De la cuestión social a los 'problemas urbanos', los reformadores y la población de las ciudades a principios del siglo XIX"; en Revista internacional de ciencias sociales; UNESCO; set. 1990. Perrot, Michelle; "La ville et ses faubourgs au XIXe siècle"; en Baudrillard, Jean et al.; Citoyennité et urbanité; Espirit; París; 1993 y "Al la dêcouverte du fait social: 1890-1900"; Calman-Lévy; París; № 2, dez.
}

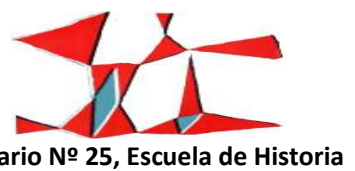


Ver la ciudad y traducirla en discursos e imágenes implica un fenómeno de percepción, pero que envuelve un complejo conjunto de "lógicas sociales". Como refiere Montlibert ${ }^{34}$ estos procesos implican juicios sociales, experiencias, recuerdos y posiciones estéticas en cuya base se encuentra la operación práctica del hábitus del al que se refiere Bourdieu. Siendo el hábitus una "adquisición" o un "capital" que se incorpora social e históricamente, él opera como una máquina transformadora que hace que "reproduzcamos" las condiciones sociales de nuestra propia producción, aunque de una manera relativamente imprevisible ${ }^{35}$. Las representaciones del mundo social así constituidas, que clasifican la realidad y atribuyen valores, en nuestro caso, al espacio, la ciudad, la calle, los barrios, los habitantes de la urbe, no es neutra ni refleja puramente un entorno "objetivo", no obstante implica atribuciones de sentido en consonancia con las relaciones sociales asimétricas atravesadas por el poder. ${ }^{36}$

De modo que las calificaciones de peligrosa o segura, limpia o sucia, ordenada o anárquica, bella o fea para una ciudad variaban de acuerdo a los productores o consumidores del espacio. Incluso con base en ese mismo razonamiento podemos afirmar que hay "lectores privilegiados" de la ciudad, con habilitaciones culturales, profesionales y estéticas que los dotan de una mirada refinada, sensible y sutil. Es el caso de los citados escritores, fotógrafos y pintores de lo urbano, que rescatan las posibilidades de lo real vivido, estableciendo con la ciudad una relación privilegiada de percepción.

Esto no quiere decir para el historiador que los "hombres comunes" no estén dotados de sensibilidad o sean incapaces de elaborar representaciones. Sin embargo, rescatar estas representaciones implica seguir un camino que tiene otras vías, distintas a la fotografía bien encuadrada y significativa, la obra de arte, la novela urbana o la crónica bien escrita. Leer la ciudad de los excluidos, los pobres y los marginales conduce al historiador a "barrer la historia a contrapelo", como afirma Walter Benjamin, buscando los fragmentos, vestigios o voces de aquellos que figuran en la historia como "pueblo" o "masas" o que se encontraban a contramano del orden, como marginales. Es en los registros policiales, en las entrelíneas de los periódicos, en las "columnas del pueblo" de los periódicos, en las fiestas populares y en las manifestaciones de las calles, en los deportes y las atracciones culturales, en los acontecimientos singulares que quiebran la rutina de la vida urbana, allí podemos encontrar sus voces o rescatar los indicios

\footnotetext{
${ }^{34}$ Montlibert, Christian; de L'impossible autonomie de l'architecte; Ob. Cit.

${ }^{35}$ Bourdieu, Pierre; Questions de sociologie; Minuit; París; 1980.

${ }^{36}$ Bourdieu, Pierre; Ce que parler veut dire; Fayard; París; 1982.
}

48

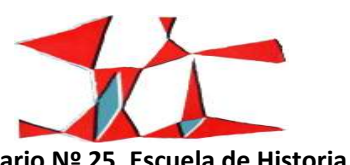


de lo que sería su mundo, llegando a las representaciones colectivas de la "otra" ciudad. Como consideración final sobre estas diferentes percepciones de lo urbano, hay que recordar la "circularidad cultural" que permite el cambio de signos entre lo que se podría llamar la "ciudad real vivida" de los consumidores de la urbe y la "ciudad soñada" de los productores del espacio, o incluso entre la contradicción de los excluidos del sistema, a "contramano" de la vida, y la ciudad ordenada, bella, higiénica y segura de las propuestas burguesas.

Pero rescatar las sensibilidades pasadas, intentar recuperar las construcciones imaginarias de los hombres de otrora, cuya vivencia corre por fuera de nuestra experiencia sensible, constituye sin duda un impasse. Tratándose del pasado, ¿cómo restablecer la relación entre sensaciones y recuerdos, como vincular la vivencia y la memoria?

Para usar la metáfora proustiana, para Proust el historiador representaría la madeleine, que, por su gusto, sabor y textura, reconstruiría la experiencia a través de la evocación. Como dice Italo Calvino ${ }^{37}$ una ciudad incluye a muchas, $y$, al analizar una metrópolis mediante lo que vemos hoy de ella, mediante en lo que ella se convirtió, es posible recordar aquello que fue un día.

Naturalmente, la forma de la ciudad, sus predios y movimientos cuentan una historia no verbal de lo que la urbe ha sido, pero, por más que este patrimonio haya sido preservado, los espacios y sociabilidades se alteran inexorablemente, sea en cuanto forma, función o significado. En el caso de las ciudades modernas, metrópolis de hecho o por atribución de sus habitantes que la ven y sienten como tal, la complejidad de la vida y las sucesivas intervenciones urbanísticas son agentes de descaracterización de la ciudad. Ocurre muchas veces que lo que podría llamarse una "pasteurización" o uniformidad de lo urbano en el peor de los sentidos la destrucción de la memoria, la sustitución de lo "viejo" por lo nuevo, la uniformización de las construcciones y la generalización del carácter de impersonalidad al contexto urbano.

En un fascinante estudio, Richard Sennett ${ }^{38}$ se pregunta frente a un problema cultural de la ciudad moderna: ¿cómo hacer hablar de este medio impersonal, cómo traspasar su neutralidad? El ejemplo del centro de Porto Alegre viene inmediatamente a la memoria. Difícil es vislumbrar, en la actual calle

\footnotetext{
${ }^{37}$ Calvino, Italo; As cidades invisíveis; Companhia das Letras; São Paulo; 1990.

${ }^{38}$ Sennett; Richard; La ville à vue d'oeil; Plon; París; 1992.
}

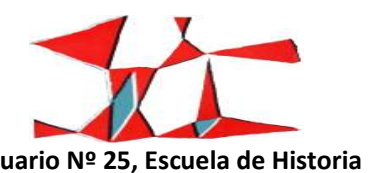


Andradas, tradicional calle de la Praia, pasarela de moda, itinerario del footing, a la antigua que desembocaba en la vieja plaza de la Alfándega con sus cines y cafés. Con las fachadas de los viejos predios recubiertas de revoques, revestimientos y afiches, los viejos espacios cediendo lugar a los nuevos usos bingos, agencias de loterías y tiendas populares de discos- muy poco queda de aquella Rua da Praia celebrada en la prosa y el verso por los cronistas y los poetas.

La postura de Sennett se opone a la de Kevin $\operatorname{Lynch}^{39}$ que atribuye una cualidad visual particular a lo urbano. Lynch apuesta a lo que llamaría una "claridad" aparente, transparencia o legibilidad del paisaje de la ciudad. Para este autor reconocer los elementos visualmente expuestos y organizados en un sistema coherente y comprensible de lo urbano sería una tarea fácil. Sennett ${ }^{40}$ señaló que las formas visuales de la legibilidad en la concepción del espacio urbano no están revestidas de un contenido tan simple o directo. 0 sea, ante la neutralidad impuesta por la acción del urbanista, la ciudad no se revelaría tan transparente. La propia cotidianeidad de la vida es también, un elemento de alteración del espacio y de transformación el medio ambiente.

Lo interesante en la visión de Sennett consiste en apostar justamente a una de las características de la ciudad moderna como elemento revelador de significados. Se trata de la capacidad de la gran ciudad de ofrecer la experiencia de la alteridad, dadas las condiciones diversas y múltiples que la vida urbana ofrece. Como dice Sennett, la ciudad es un lugar que autoriza a las diferencias y que anima a la concentración de esas diferencias, constituyendo identidades dispares y experiencias cada vez más complejas.

Así, bajo el imperio de la diversidad es que Sennett postula una nueva mirada, defendiendo el poder de la interpretación visual que podría conquistar la experiencia de la complejidad del medio urbano.

De esta forma, todo aquello que antes representaría elementos de perturbación es descaracterizado -la impersonalidad, el anonimato, la diferencia, la complejidad, la separación entre interior y exterior, entre lo público y lo privado- puede tornarse un elemento de reeducación de la mirada, permitiendo una revelación o una nueva coherencia para el mundo.

\footnotetext{
${ }^{39}$ Lynch, Kevin; A imagem da cidade; Edições 70; Lisboa; 1990.

${ }^{40}$ Sennett, Richard; La ville à vue d'oeil; Ob. Cit.
}

50

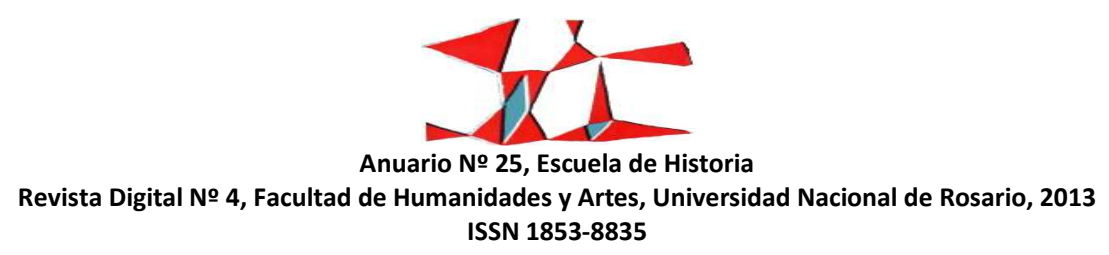


La perspectiva de Sennett, que enfatiza la necesidad de cambio de perspectiva de mirar sobre lo urbano, es una propuesta que se liga a otros espectadores y/o pensadores de lo urbano. Al comienzo, el propio Sennett invoca a la figura de Charles Baudelaire, quien vio en París la posibilidad de una trascendencia de la mirada, tales las correspondencias pasibles de ser aprendidas por las múltiples figuras, por los múltiples espacios y prácticas sociales que la ciudad ofrecía. La figura del flâneur que vaga por la ciudad, en la maraña de calles y personajes, es la de alguien que tropieza con obstáculos, se enreda en las conversaciones y se confronta con signos a descifrar ante la ambivalencia de la vida cotidiana. Navegando en el azar que se da cita sobre la calle, el poeta capta la diversidad de la vida y hace emerger el contraste y lo paradójico en su representación de lo urbano. ${ }^{41}$

La idea del contraste produciendo la revelación o el descubrimiento podría ser ejemplificada en varios momentos de los famosos Tableaux parisiens de Baudelaire, pero nos referiremos a uno sólo encarnado por la poesía À une mendiante rousse $e^{42}$, en el cual el autor opone a la figura patética y bella de una joven mendiga la saña e estupidez de los "laberintos" que exploran su fragilidad. La crítica social y la opresión de los humildes emergen de la imagen de contrastante expresada de poéticamente. En este contexto, Baudelaire recompone algunas representaciones de lo urbano que operan como valor de síntoma de una época.

Walter Benjamin, lector de Baudelaire así como de Proust, despliega también una especie de método de montaje por contraste con el fin de posibilitar la revelación o “iluminación". Cortando los vínculos genéticos pasado/presente, lo que Benjamin postula es la creación de contra-imágenes que rompan en continuo de la historia, propiciando lo que se llamaría "el salto del tigre", que daría margen a la inteligibilidad por el contraste. ${ }^{43}$ Pero esto no implica que Walter Benjamin no privilegie la teoría y la construcción de conceptos para el entendimiento de las representaciones de lo social, en este sentido, propone las categorías de "dialéctica suspendida" o de "fantasmagoría", versión Benjaminiana del fetichismo de la mercancía de Marx ${ }^{44}$.

\footnotetext{
${ }^{41}$ Labarthe, Patrick; "París comme décor allégorique”; en Avice, Jean Paul y Pichois, Claude (dir.); Baudelaire, París, I'allégorie; Klincksieck, París; 1995.

${ }^{42}$ Baudelaire, Charles; Les fleurs du mal; Gallimard; París; 1972.

${ }^{43}$ Rüssen, John; "La história, entre modernidad y post-modernidad”; Ob Cit.

${ }^{44}$ Benjamin, Walter; "París, capitale du XIXe siècle”, Le livre des passages; CERF; París; 1989.
}

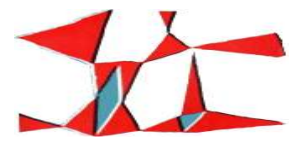

Anuario № 25, Escuela de Historia Revista Digital № 4, Facultad de Humanidades y Artes, Universidad Nacional de Rosario, 2013 ISSN 1853-8835 
Lo que cabe rescatar en este momento es el método del que se vale Benjamin para, a través del cruzamiento de imágenes contrarias, obtener la revelación de la coherencia de sentido de una época. Analizando la obra de Benjamin, Willi Bolle indica la técnica de montaje, tomada en prestada de las vanguardias artísticas, en especial del cine y su transposición en la historia. ${ }^{45}$ Según Bolle, la historiografía benjaminiana, como construcción, presupone un trabajo de "destrucción" o "desmontaje" de aquello que el pasado ofrece, apuntando a una nueva construcción dictada por el ahora. Así, surge el montaje en forma de "choque" o contraste, confrontando las imágenes antitéticas y, por consiguiente, dialécticas, para promover el "despertar" o la "revelación". Expliquémonos: una metrópolis propicia a sus habitantes representaciones contradictorias del espacio y de las sociabilidades que allí tienen lugar. Ella es por un lado, luz, seducción, centro de la cultura, civilización y sinónimo de progreso. Pero, por otro lado, ella puede ser representada como amenazadora, centro de perdición, imperio del crimen y de la barbarie, mostrando una faceta de inseguridad y miedo para quien en ella habita. Son, sin dudas, visiones contradictorias, de atracción y repudio, de seducción y rechazo, que, paradójicamente, pueden convivir en el mismo portador. Esta sería incluso, como recuerda Marshall Berman ${ }^{46}$, una de las características de la modernidad en cuanto experiencia histórica individual y colectiva: la postura de celebración y de combate delante de lo nuevo, que en parte ejerce fascinación y en parte atemoriza.

Así es que, siguiendo la estrategia metodológica del montaje, siguiendo el choque contrastaste, es posible poner frente a frente las representaciones de la ciudad que hablan del progreso o de la tradición, las que celebran lo urbano o el ideal rural, el imaginario de los consumidores del espacio frente al de los productores de la urbe, la visión de las élites urbanas y la de los sectores populares, la dimensión de la esfera pública, en cuanto representación, y el imaginario construido sobre lo privado, las imágenes del espacio que contraponen el centro al barrio o aún la propia visión de la calle, vista como lugar de paseo o pasaje, contrapuesta a aquellos que en ella viven por carecer de otra opción.

Aun obedeciendo al principio de desmontaje y remontaje de los fragmentos de lo urbano, obtenidos por las ideas y las imágenes de la representación colectiva que son contrastadas como el intento de revelar una nueva constelación de significados, Willi Bolle indica otra técnica de inteligibilidad: el montaje por

\footnotetext{
${ }^{45}$ Bolle, Willi; A fisionomia da metrópole modern; Companhia das Letras; São Paulo; 1994.

${ }^{46}$ Berman, Marshall; Tudo que é sólido desmancha no ar; Ob. Cit.
}

52

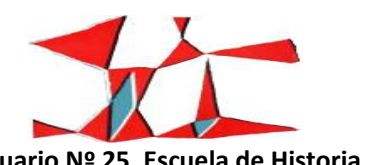


superposición. Argumenta que esta sería tal vez "la más propicia para radiografiar el imaginario colectivo", pues en ella la toma de conciencia se daría a poco a poco y no por efecto de la revelación por choque, mencionada arriba. Sería el proceso metodológico a través del cual el historiador iría yuxtaponiendo personajes, imágenes, discursos, eventos, performances "reales" o "imaginarias" del espacio urbano.

Se trataría de la técnica que más se aproxima a lo que comúnmente se llamaría la contextualización, el referencial de circunstancia o incluso el cuadro de contingencias que demarca la situación al ser analizada. Así es que, en la ciudad, comparecerían, como fragmentos de la historia o actores al ser yuxtapuestos unos a otros, la multitud y el flâneur, el pueblo y un destacado personaje, negros, mujeres, marginales, políticos, callejones y avenidas, fiestas, rituales, cotidianeidad y eventos excepcionales.

Frente a esta estrategia un historiador recoge fragmentos expresados en discursos e imágenes que hablan del pasado, intentando aproximarse al imaginario colectivo de una época $-y$, por tanto, representando lo ya representado-, es imposible dejar de pensar en Carlo Ginzburg ${ }^{47}$, como en sus consideraciones del historiador detective. Ginzburg defiende que el conocimiento del historiador es fragmentario e indiciario. Tal como lo hacían Freud o Sherlock Holmes, opera de forma detectivesca recogiendo los síntomas, indicios y pistas que combinados o cruzados permiten ofrecer deducciones y develar significados. En ocasiones, la constitución de un paradigma indiciario no se ata a la evidencia manifiesta, pero si a los detalles, a los signos episódicos, a los elementos de menor importancia, marginales y residuales, que, con todo, permitiría el desciframiento del enigma o desatar un enredo.

El rigor de las técnicas de montaje por yuxtaposición y contraste no sólo no son excluyentes, puesto que en la práctica los historiadores tanto se valen de una o de otra, contextualizando y oponiendo imágenes de discursos antitéticos en la búsqueda de significados y correspondencias.

Apoyado en un nuevo paradigma centrado en la cultura, utilizando conceptos tales como los de representación y de imaginario o el principio del cruzamiento de las prácticas sociales con las imágenes y discursos de la representación de lo real, soportado en la estrategia metodológica detectivesca del montaje por contraste o yuxtaposición, resta al historiador la difícil tarea de rescatar lo que pensaban o intentaban expresar los hombres del pasado.

${ }^{47}$ Ginzburg, Carlo; “Raízes de um paradigma indiciário”; en Ginzburg, Carlo; Mito, emblemas, sinais; Companhia das Letras; São Paulo; 1990.

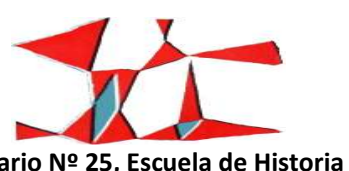


Si el pasado es un "lugar" distante, si llega a nosotros como un "tiempo no experimentado", donde ocurrieron hechos "no observables", las voces de este pasado pueden sonarnos extrañas, y sus imágenes pueden parecer incomprensibles para nuestra contemporaneidad. En ocasiones, da la impresión de que hay un "ello" perdido que perpetúa los enigmas de otro tiempo. Rescatar las representaciones colectivas antiguas no significa juzgarlas con los instrumentos mentales de nuestro tiempo, pero si intentar captar las sensibilidades pasadas, cruzando aquellas representaciones entre sí y con las prácticas sociales corrientes. Es sobre todo, recordar la actualidad de las palabras de Lucien Febvre "De hecho, un hombre del siglo XVI debe ser inteligible no con relación a nosotros, sino en relación a sus contemporáneos." ${ }^{48}$

$\mathrm{Y}$, como regla general de una historia urbana, cabe recordar que todo esfuerzo para develar representaciones pasadas es una lectura entre otras posibles. El lector del presente -historiador empeñado en construir las representaciones del pasado- lidiará con las dificultades del filtro del tiempo, las dificultades de acceso a los códigos y significados, la extrañeza del lenguaje y de las prácticas usuales, o el inevitable reverso del ocultamiento en la construcción de discursos, dispersión y dificultades de acceso a las fuentes $y$, especialmente, con la certeza de lidiar con materiales que ya le llegan en forma de representación. Si las representaciones más fáciles de rescatar son aquellas que resultan de un acto de voluntad o de un ejercicio de poder -las identificaciones urbanas atribuidas a través de una elaboración deliberada e intencionalidad difundida-, pero mucho más costosa será la aprehensión de contra-imágenes construida por los usuarios de la ciudad, reiteración en parte de tradiciones inmemoriales, deseos no realizados o metabolizados y traducción de valores impuestos.

En este entrecruzamiento de espacio y tiempo, la ciudad aparece como un bosque enmarañado de símbolos, que pueden tornarse inteligibles para el historiador o, por el contrario, se configuran como obstáculos. Es en este contexto que gana expresión la "teoría del laberinto" de Abraham Moles ${ }^{49}$. Entendiendo como un arquetipo fundamental de la organización de un espacio restringido, o laberinto es construido de muros, prohibiciones, falsas salidas, pero también de corredores a través de los cuales es posible hallar caminos.

\footnotetext{
${ }^{48}$ Febvre, Lucien; O Problema da Incredulidade no século XVI. A religião de Rabelais; Companhia das Letras; São Paulo; $2009 ;$ p.13.

${ }^{49}$ Moles, Abraham; "Labyrinthe ou nébuleuse"; en Espace Temps. Voyage au centre de la ville. Éloge de l'urbanité; № 33; París; 1986.
}

54

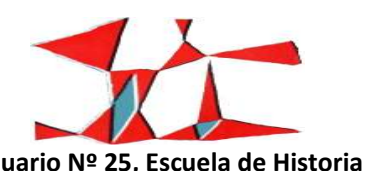


La ciudad es un laberinto de experiencia eternamente renovable, donde el individuo que en él se adentra no es un ser completamente perdido o sin rumbo. Es alguien que trabaja con memoria y sensación, experiencia y bagaje intelectual, reconociendo los microestímulos de la ciudad que presentan caminos que se abren o cierran. ${ }^{50}$ Para enfrentar esta tarea, el moderno lector de lo urbano habrá de contar con su bagaje previo, con su "capital" de historiador: no sólo un universo conceptual e instrumental metodológico, sino también un conjunto de conocimientos acumulados sobre lo urbano que las generaciones anteriores ya produjeron. A partir de esta base, enfrentará el desafío de cruzar referencias, practicas y representaciones, datos objetivos y percepciones subjetivas, yuxtaponer, contrastar y sobre todo, mantener una predisposición y una apertura para observar un poco más allá, tal vez, de aquello que ya fue visto, desplegando en el presente las múltiples ciudades del pasado que las que hoy existen encierran. $Y$, para recurrir a las metáforas que los clásicos nos brindan, de esta forma podrá la nueva mirada de Clio orientar los caminos de Ariadna.

${ }^{50}$ Moles, Abraham; Labyrinthes du vécu; l'espace, matière d'action; Librairie Méridiens; París; 1984.

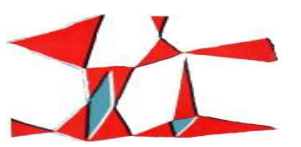

Anuario № 25, Escuela de Historia 